\title{
Manchetes de jornal: a criação de um caso
}

COM A MESMA RAPIDEZ que cria imagens, conceitos ou mitos, a mídia pode destruí-los, rápida e vorazmente. A presença e os efeitos deagenda-setting são uma realidadepal pável.

O "caso" Habitasul, ocorrido em 1985 e utilizado neste estudo de agenda-setting, é peça perfeita para demonstrá-lo.

A dimensão do trabalho abarca somente a agendadosmeios decomunicação, não sendo possível, por falta de recursos necessários, abranger a agenda dos leitores.

No ano de 1985 foram decretadas pelo Banco Central do Brasil intervenções e liquidações deváriasempresasfinanceirasgaúchas, como decorrência da crise nacional do Sistema Financeiro, especialmente no setor habitacional , que, em nosso Estado, seviu agravada pela liquidação do Banco Sulbrasileiro. O Grupo Habitasul, por exemplo, tomou a iniciativa de solicitar ao Banco Central a intervenção em suas empresas financeiras.

A imprensa logo precipitou-seà apuração de fatos e estórias, em paralelo ou mesmo antecipando-seao Banco Central, criandouma pauta especial eo seu próprio "caso" sobrea crisedo Sistema Financeiro do Rio Grandedo Sul, comversão, al iás, não coincidentecomos fatos finalmente conhecidos e confirmados quando do término oficial dasinvestigaçõese das intervenções.

\section{A teoria do agenda-setting}

Patricia Muscariello Fossati Mestranda em Comunicação Social FAMECOS/ PUCRS
“O princípio geralmente aceito é o de que o que está escrito é verdade, pois a informação escrita fornece aos leitores uma indicação de importância 'sólida, constanteevisível'." (McClureePatterson 1976, p.26) 
A teoria de agenda-setting apresenta-se como um conjunto integrado de pressupostos e de estratégias depesquisa. A hipótesedeagen dasetting defende que:

“Em conseqüência da ação dos jornais, da televisão e dos outros meios de informação, o público sabe ou ignora, presta atenção ou descura, realça ou negligencia elementos específicos dos cenários públicos. As pessoas têm tendência a incluir ou excluir dos seus conhecimentos aquilo que os mass media incluem ou excluem do seu próprio conteúdo. Além disso, o público tendeaatribuir àquiloqueesseconteúdo inclui uma importância que reflete de perto a ênfase atribuída pelos mass media aos acontecimentos, aos problemas, às pessoas." (Shaw, 1979, p.96)

O estudo sobre os efeitos de agenda-setting partiu de premissas descritas por Schultz (apud Wolf, 1993, 123-124), como:

“a) os processos comunicativos são assimétricos: existeumsujeito ativo que emite o estímulo e um sujeito passivo queéimpressionado por esseestímuloe que reage;

b) a comunicação é individual; é um processo quediz respeito, antes do mais, acadaindivíduo equedeveser estudado nesses indivíduos;

c) a comunicação éintencional; o início do processo, por partedo comunicador, acontece intencionalmente e dirige-se em geral a um objetivo; o comunicador visa a um determinado efeito;

d) os processos comunicativos são episódicos: o início e o fim da comunicação são limitados no tempo, e os episódios comunicativos têm um efeito isolável eindependente."

Na problemática dos efeitos tem-se a relação entre a ação constante dos mass media e o conjunto de conhecimentos acerca da realidade social.

Nessarelação, sobressaem-seascaracterísticas de acumulação (a mídia é capaz de criar e manter relevância de certos temas); de consonância (traços comuns mais numerosos do que as diferenças nos comportamentos das diferentes mídias); e de onipresença (transformação de um conjunto quantitativo de informações de domínio apenas dos veículos e passado para o público como novidade).

Sobre a teoria, de um modo geral, pode-se dizer que é uma tentativa generalista, multidisciplinar, onde o público passa a ser fonte de informação e de avaliação, considerando quehá movimentos cíclicos do público de valorização ou não sobre um assunto.

O objetivo principal destetrabal ho éo resgate do processo deagendasobreumtemaregional de repercussão nacional. O caso Habitasul presta-seaessetipo deobservação, poisreflete a ênfase dada pela imprensa diariamenteaos acontecimentos ligados ao tema, aos problemas eàs pessoas envolvidas.

Por que as manchetes são tão importantes

“(...) É muito comum o leitor afirmar que leu o jornal, quando somente viu a notícianostítulos." Douglas(1966, p.26)

Levando-se em consideração a pesquisa realizada por McClure e Patterson, que concluiu que as diversas mídias possuem uma capacidade diferente para estabelecer a ordem do dia dos assuntos publicamente importantes equea informação escritaémais influente do que a televisão, foi escolhida para este estudo a mídia impressa, com os seguintes veículos: em Porto Alegre, Jornal do Comércio e Z ero H ora; e na cidade de São Paulo, Gazeta M ercantil. As informações se 
distribuem em vários níveis na mídia impressa. Para Lage(1990, p.6-7), eles são em número detrês: o projeto gráfico, os sistemas analógicos e o sistema lingüístico. Neste último, estão asmanchetes, ostítulos, ostextos easlegendas, querepresentamo componente digital da comunicação jornalística.

Como, nas línguas naturais, a sintaxelógicaé ricaecomplexa, fazendo dosistemalingüístico o maisadequadoà comunicação deconceitos, nossaunidadedeanálisedestetrabal ho foram asmanchetes veiculadasna primeiraeúltima páginas dos jornais, pois um assunto fortemente valorizado no jornal diário tem quase todas as probabilidades de sê-lo também na agenda dos leitores.

As manchetes têm a responsabilidade de resumir a notícia, constituindo o fator que determina seela vai ser posta delado ou lida. Douglas afirma que os leitores são, em sua maioria, leitores de manchetes (1971, p.15): “É comum o leitor afirmar que leu o jornal, quando somente viu a notícia nos títulos [manchetes]."

Asmanchetes variam, conformeo texto aque sereferem, em manchete-assunto, manchetefixa e manchete-notícia.

Esta última, que é a relevante para os propósitos deste trabalho, adota, conforme Douglas (1966, p.16), o mesmo processo do lead, masem grau mai senfático, ao condensar os elementos essenciais da notícia. Segundo ele, a "manchete-notícia” éaqueleenunciado que procura atingir mais profundamente $o$ leitor, constituindo-se, por si só, nanotíciaem sua expressão mais simples. Diz esse autor que "osjornaissão planejados para informar, einformar rapidamente".

A opção pelas manchetes-notícia que foram veiculadas na primeira eúltima páginas dos jornais deveu-se à compreensão que se tem dequeum assunto fortementevalorizado no jornal diário tem quase todas as probabilidadesdesê-lotambémnaagendadosleitores.
Mídia: agente ativo na seleção, enfoque, interpretação e enfatização dos a contecimentos

“Pouco podemos ver, por nós mesmos, porque dependemos dos produtos da comunicação de massa para a grande maioriadasinformaçõesquerecebemos em nossa vida."(William L. Rivers e Wilbur Schramm, apud Erbolato, 1991, p.51)

Foi realizado um levantamento dedados, nos meios impressos citados, durante o período de 11 de fevereiro a 11 de março de 1985, através das manchetes-notícia veiculadas na primeira eúltima páginas dos jornais.

Para sel ecionar essas manchetes, levaram-se em conta as seguintes premissas:

a) considerou-se como objeto de estudo qualquer manchetenotícia sobre o tema, independentementedesetratar demanchete principal ou secundária, veiculadanaprimeira ou última página dos jornais em questão;

b) manchetes ou chamadas com a mesma indicação depágina ou numeração depáginas contínuas foram consideradas como uma só;

c) manchetesou chamadas com indicações de páginas diferentes, correspondentes a seções distintas dentro do corpo do jornal, foram contadas de acordo com o número de indicações correspondentes.

d) todas as legendas de fotos sobre o tema foram desconsideradas, mesmo estando na primeira ou última página.

O leitor foi fortemente induzido a pensar sobre o assunto, pelo fluxo contínuo de informações. Através dos três jornais, as pessoas ficaram expostas às notícias sobre 0 caso durante vinte dias, do total de trinta observados. Do dia 11 ao dia 27 de fevereiro de 1985, as publicações foram diárias, considerados os três jornais analisados. A 
análise das manchetes de primeira e última páginas dos jornais revela que, durante todo o período sel ecionado, a mídia citadacolocou o caso em suas capas, fazendo com isso com que os seus leitores incluíssem nos seus interesses esse mesmo tema.

Duranteos dias 13, 15, 20 e21 defevereiro e6 de março de 1985, os três jornais analisados trouxeram o assunto nas suas primeiras e últimas páginas. Já a coincidência entre a Z ero H ora e o Jornal do Comércio mostra que, durante dez dias, na mesma data, o caso foi mancheteentreasprimeiraseúltimaspáginas desses jornais. Sob o ponto de vista da tematização, ou seja, de como o caso em pauta é inserido na hipótese de agenda-setting, focalizou-se o rel evo dado a ele pela mídia, a suasaliênciaeo seu significado a partir dasua veiculação freqüenteesobretudo na primeira e última páginas dos jornais. $O$ fato é que 0 acontecimentoemquestãotransformou-seem assunto significativo, num "caso", poder-seia dizer, para os sul-rio-grandenses, estendendo-se a outros estados, como aconteceu com São Paulo, por estar inserido num contexto de crise nacional do Sistema Financeiro no ano de 1985.

Estabeleceu-se um processo circular através da exposição dos fatos pela mídia, do surgimento do interesse público sobre estes fatos e dos destaques diários sobre os acontecimentos por parte da mídia. O tema atingiu emcheio osrio-grandenses, poistinha todososingredientes paraenvolvêlos. Como a hipótese de agenda-setting constrói-se a partir de um interesse geral sobre o modo como as pessoas estruturam sua realidade, este tema, ao tocar profundamente nos interesses individuais, pois relacionava-seao fechamento de agências bancárias onde a população possuía dinheiro aplicado, estimulou a publicação de histórias, a sensibilização do público, e realimentou a freqüência do noticiário.

A hipótese de agenda-setting trata da influência cumulativa e dos efeitos a longo prazodainformação. Por isso, podemosdizer que, no caso Habitasul, a mídia conduziu sua pauta objetivando adaptar as pessoas a ela e construir uma imagem, para si própria, de agente ativo na percepção de grandes problemas regionais enacionais empenhado emencaminhá-losao conhecimento detodos. Porfim, cabeareflexão dequeo tema versado é rico e abre um universo de proposições e indagações, em extensão e profundidade, desde as mais simples às mais complexas.

\section{Referências}

AMARAL, Luiz. Jornalismo: Matéria de primeira página. Rio de Janeiro, Tempo Brasileiro, 1982.

BELTRÃO, Luiz. A imprensa informativa. São Paulo, Folco Masucci, 1969.

DEFLEUR, Melvin L. e BALL-ROKEACH, Sandra. Teorias da Comunicação de M assa. 5.ed. Rio de Janeiro, Jorge Zahar Editores, 1993.

DOUGLAS, Joaquim. Jornalismo: A técnica do título. Rio de Janeiro, Agir, 1966.

ERBOLATO, Mário. Técnicas de codificação em jornalismo. 5.ed. São Paulo, Ática, 1991.

FOLHA DE SÃO PAULO. M anual geral de redação. 2.ed. São Paulo, Folha de São Paulo, 1987

.GAZETA MERCANTIL. São Paulo, 11 fev. / 11 mar. 1985

JORNAL DO COMÉRCIO. Porto Alegre, 11 fev. / 11 mar. 1985

LAGE, Nilson. Linguagem jornalística. 3.ed. São Paulo, Ática, 1990.

WOLF, Mauro. Teorias da Comunicação. Lisboa, Editorial Presença 1987.

ZERO HORA. Porto Alegre, 11 fev. / 11 mar. 1985. 